\title{
Sputniks cubanos. De cómo la URSS ocupó la imaginación de una generación
}

Cuban Sputniks. About how the USSR occupied the imagination of a whole generation

\author{
JUAN CaRlos TOLEDANO REDONDO
}

Lewis and Clark College·toledano@lclark.edu

Juan Carlos Toledano Redondo (Adra, España) estudia lo fantástico en la narrativa contemporánea en español. Entre su producción académica destacan "Una cartografía de la CF cubana a través del trabajo de Yoss" (Lo fantástico en Hispanoamérica, 2012), "The Many Names of God: Christianity in Hispanic Caribbean Science Fiction" (Chasqui, 2007), y "From Socialist Realism to Anarchist Capitalism: Cuban Cyberpunk" (SFS, 2005). Es co-editor de la revista académica de cf\&f Alambique, y Profesor Titular de Estudios Hispánicos en Lewis and Clark College, Portland, Oregón (EE.UU.).

RECIBIDO: 17 DE MARZO DE 2015

ACEPTADO: 5 DE JUNIO DE 2015

Resumen: A pesar de la cierta marginalidad de la ciencia ficción en Cuba, ésta no estuvo exenta de la influencia cultural que sufrió la isla al sovietizarse. De la URSS y el entorno comunista llegaron cientos de obras del género, al mismo tiempo que la producción local se reducía a cero en los años setenta. Los autores cubanos tomaron partido, unos defendieron los nuevos estilos e ideas venidos del Este; otros decidieron seguir su camino, algunas veces, a contracorriente.

Palabras Clave: Cuba, URSS, cuento, estrategia literaria, identidad.

\begin{abstract}
Despite the somewhat marginalization of science fiction in Cuba, the genre could not avoid the cultural influence that the island experienced when it adopted Soviet cannons. From the USSR and the Communist allies came hundreds of genre publications in the seventies, while local production was reduced to zero. Most Cuban writers took sides, some defended the new styles and ideas that came from the East; others decided not to, and even created sometimes a counter discourse.
\end{abstract}

Key Words: Cuba, USSR, storytelling, literary strategy, identity.

DOI: 10.7203/KAM.5.4993 
En el verano del 2009, el ensayista, escritor y organizador de congresos de ciencia ficción (cf) Bruno Henríquez, editó en Cuba El hombre que hizo el mar Báltico, colección recopilatoria de cuentos "rusos" (sic) (en su época soviéticos) que fueron publicados en Cuba a partir de los sesenta. En la colección se encuentran autores tan conocidos como los hermanos Strugatski, Alexánder y Serguéi Abramov (padre e hijo) u Olga Larionova, entre otros. Según Henríquez, publicó esta colección para “(...) hacer un homenaje a los autores rusos--incluidos o no--que nos trajeron otra visión del mundo e influyeron en nosotros de las más diversas maneras"; habiendo indicado antes que esos "nuevos enfoques" no anglosajones (sic) se producían tanto "por las especulaciones de los autores como por las lecturas entre líneas” (Henríquez, 2009: 3).

Esta añoranza de una época pasada, pero que de alguna forma retorna hoy, se demuestra dentro y fuera de Cuba. La feria del libro de 2010 estuvo dedicada a Rusia, Putin ha retomado las relaciones con la isla y condonado la deuda con la URSS casi en su totalidad, y en EE.UU. se unieron cubanos de dentro y fuera de la isla a otros estudiosos de la relación entre ambos países y realizaron un pionero congreso sobre la relación Cuba-URSS en la Universidad de Connecticut, en enero del 2007¹, y ya ahora esta revista que tiene $\mathrm{Ud}$. en sus manos (es un decir) contiene artículos de algunos de aquellos mismos participantes y temas. Sin embargo, mi intención no es hablar de la nostalgia sino trasportarnos directamente al pasado y relatar el por qué de esta relación entre entidades tan dispares como Cuba y la URSS, y sobre todo, cómo esta relación se fragua en algo tan en ocasiones marginal como puede llegar a ser la producción de cf. Para ello, haré una breve relación del desembarco de la cf del Este en Cuba en los setenta y de la reacción que ésta produjo en algunos ejemplos de la cf local, principalmente alrededor de los autores premiados con el David de cf. Como veremos, no todos los autores reaccionaron plegándose a las directrices culturales oficiales, e incluso estas diferentes reacciones nos permite agruparlos para analizar su obra mejor.

Quizá el inicio de este relato no se pueda entender sino simbólicamente, cuando un 4 de octubre de 1957, la URSS puso en órbita el Sputnik y se aceleró la carrera espacial espoleada por la Guerra Fría. En una de las antenas del satélite subió también la imaginación de millones de personas, sueños que después se plasmaron en miles de relatos de cf. Un género que ya estaba arraigado en Europa desde el siglo XIX y que precisamente mantuvo una relación de amor y odio con la URSS. El género era lo suficientemente popular como para necesitar la atención de las autoridades soviéticas, quienes trataron de controlar sus mensajes y crear, como dice Henríquez "una ciencia ficción triunfalista que planteaba un

\footnotetext{
${ }^{1}$ El congreso se llamó Cuba-URSS y la experiencia post-soviética, y fue organizado en la Universidad de Connecticut, y en los salones del Instituto Cervantes de Nueva York por la profesora Jacqueline Loss y el escritor José Manuel Prieto .
} 
futuro dominado por el socialismo, en especial soviético" (Henríquez, 2009: 3). El estudioso español, Ignacio Ferreras, tiene uno de los ensayos seminales sobre cf. Nos recuerda que Lenin defendía el eslogan "Sóviets más electricidad" (Ferreras, 1972: 112) para defender la fe científica en el futuro de la URSS. Pero además nos relata que esa fe no vino sin intervención ideológica del Estado y que ya en 1931 el estalinismo prohibió la cf en nombre del "realismo"; que más tarde, en 1947, el ideólogo y férreo defensor del realismo socialista, Andréi Jdanov, obligó al uso de temáticas exclusivamente relacionadas con el plan quinquenal estalinista; para finalmente llegar a 1971, cuando Boris Markov recomendó que solamente se usasen temáticas sobre producción (Ferreras, 1972: 112).

Una vez ideológicamente regulada, la cf se convirtió en la aliada natural de la eutopía ${ }^{2}$ socialista. Mientras que en otros lugares, la cf se había convertido en la herramienta que denunciaba los posibles miedos y abusos del futuro ${ }^{3}$, la cf soviética era aliada de la eufórica construcción socialista del universo. No es baladí que una de las películas que inauguren el género cinematográfico de cf sea la versión fílmica de la novela de Alekséi Nikoláyevich Tolstói Aelita, reina de Marte, dirigida en 1924 por el director soviético Yakov Protazánov, y donde los protagonistas soviéticos realizan una revolución bolchevique en Marte.

La URSS, como bien nos indica Roselind J. March en su libro Sóviet Fiction since Stalin: Science, Politics and Literature, se había lanzado a defender un modelo de ciencia que permitía soñar con un mundo mejor. El socialismo, aliado de la implacable razón de la Ilustración y de la fe en el eterno progreso industrial positivista, llevaba la revolución de los campos de eurasia a los planetas más lejanos. Marsh hace mención de los "godbuilders" soviéticos. Estos constructores divinos representaban y estaban imbuidos del optimismo natural que la revolución socialista había impuesto en su ciencia y científicos, naves espaciales y cosmonautas (palabra que los soviéticos usaban para decir astronautas, y que muchos cubanos adoptaron), e incluso en sus novelas y novelistas. De ahí que no podamos olvidar las palabras del autor soviético Abran Tertz (seudónimo de Andrei Sinyavsky), quien después de criticar la imposición del realismo socialista en la URSS en su libro clandestino Sobre el realismo socialista de 1960, quiso plasmar sus contradicciones afirmado que "But if I have a few things against the socialist state-trifles, all of them-I have absolutly nothing against the Sóviet power. Ridiculous? Maybe. But this is also romanticism" (Tertz, 1960: 81) [Pero si tengo unas pocas cosas contra el estado socialistas-

\footnotetext{
2 Aunque poco popular, el término eutopía es mucho más específico que el de utopía. Eutopía es el opuesto de distopía, mientras que utopía sólo hace referencia a un espacio que no existe, sea este feliz o infeliz. Para más información ver: Claeys, Gregory and Tower Sargent, Lyman. The Utopia Reader.

3 Desde Frankenstain hasta Mil novecientos ochenta y cuatro, pasando por Un mundo feliz, Farenheight 451, o incluso en el cine, con Metrópolis.
} 
Juan Carlos Toledano Redondo. Sputniks cubanos...

minucias todas ellas--, no tengo absolutamente nada contra el poder soviético. ¿Ridículo? Quizás. Pero eso es también puro romanticismo].

A pesar de las Aelitas y de las contradicciones expuestas, tampoco podemos olvidar que ya en 1921 Yevgueni Zamiatin había publicado la distopía soviética Nosotros (aunque no fue editada en ruso hasta la Perestroika de Gorvachev), con lo cual la cf, como el resto de las artes, se debatía entre el apoyo y el rechazo al poder bolchevique.

Es esta muestra de contradicciones las que llevará también a Ángel Arango, uno de los que fuera máximos exponentes de la cf cubana, ha escribir en 1984 en el artículo titulado "La joven ciencia-ficción cubana. (Un lustro dentro del concurso David)", que los autores jóvenes cubanos favorecen la utopía socialista:

En lo ideológico es precisamente en lo que más se diferencian de la ciencia-ficción norteamericana que conocieron y que conocimos. Ven al mundo como constituyendo (...) una Federación Mundial, una sociedad única con un interés ecuménico que prevalece sobre los rasgos nacionales, que conservan un carácter mas bien anecdótico. Lo primordial es que esa humanidad esta organizada con fines y objetivos comunes, bajo ideas colectivas, comunistas, de amor al planeta y a los hombres. Inclusive esta sociedad, federación o gobierno mundial se describe como ocupando posiciones en el resto del cosmos. (Arango, 1984: 135-136)

El propio Arango, que en los sesenta había publicado cuentos de estilo similar al norteamericano, comenzó en 1982 a publicar la que sería su colección más significativa, y que se adecuaba perfectamente al concepto soviético triunfalista de una cf que celebraba los triunfos científicos del ser humano y que recuerda incluso al estilo soviético de escritores como Efremov y su famosa Nebulosa de Andrómeda o los hermanos Strugasky y su Cataclismo en Iris, ambas novelas muy populares en Cuba ${ }^{4}$. Aunque el rechazo a los principios del realismo socialista ya había sido rechazado incluso por nada menos que Ernesto "Che" Guevara, quien ya se planteaba en 1965 que el realismo socialista no tenía nada que ofrecer a Cuba (Guevara, 1997: 209), a finales de los años sesenta y comienzos de los setenta la realidad cultural cubana vendría marcada por el fin de la libertad intelectual en Cuba. Si aún quedaba algún espacio reducido de plena libertad, el caso Padilla acabó con él, por algún tiempo; pero el caso Padilla no fue un suceso aislado, ya que en 1971 se produjo el Primer Congreso Nacional de Educación y Cultura que determinó, entre otras cosas, que el realismo socialista era el modelo a seguir por los agentes literarios cubanos. Para la cf esto representó tres cosas: la primera fue la obligatoriedad de temas, como

\footnotetext{
${ }^{4}$ La novela inicial de la tetralogía es Transparecnia. Hay un artículo monográfico dedicado a su obra publicado en Extrapolation y titulado “Ángel Arango’s Cuban Trilogy: Rationalism, Revolution and Evolution.” (ver bibliografía).
} 
recuerda Antonio Orlando Rodríguez, el Congreso "reclamó claramente a los intelectuales revolucionarios que escribieran sobre temas de literatura infantil y de la revolución cubana" (4). La segunda consecuencia fue un vacío en publicaciones autóctonas de cf. Daína Chaviano publicó en 1988 datos editoriales de las novelas de cf, demostrando que en la década de los setenta las publicaciones cubanas del género se redujeron a cero. Por último, el intento de impulsar una ideología de estado en la cf vino acompañada de un intento de re-educación de los escritores más jóvenes a través de la masiva publicación de autores soviéticos o de la esfera socialista. Como recuerda Henríquez

(...) el mayor impacto nos llegó a través de los cuentos y novelas que aparecieron en las colecciones de editoriales rusas Mir y Ráduga, las revistas Sputnik y Literatura Soviética, así como en las ediciones cubanas de las editoriales Arte y Literatura y Gente Nueva.

Conocimos así La nebulosa de Andrómeda, 220 días en una nave sideral, Aelita, El hiperboloide del ingeniero Garin, Guianeya, Ariel, Ictiandro, Cataclismo en Iris, Viaje por tres mundos y Qué dificil es ser dios, por mencionar algunas ${ }^{5}$. (Henríquez, 2009: 3)

Esta importación de literatura de cf ideológicamente "trillada" de discursos contrarrevolucionarios, vino a terminar con la tradición existente de una cf más occidentalizada que, como indica el autor cubano Yoss, “(...) resultó inmediatamente sospechosa a los ojos de los celosos comisarios políticos tropicales. Se le acusó de literatura pesimista, antisocial, heréticamente ajena a los sagrados modelos de realismo socialista importados de la U.R.S.S." (Yoss, 2012: 65). Y es que la cf cubana se había nutrido de todas las posibles, y no sólo de la llegada desde el Norte, como bien podemos observar en la colección de Oscar Hurtado Cuentos de ciencia-ficción de 1969, en la que aparecen autores de varias nacionalidades: norteamericanos (Walter M. Miller, Ray Brádbury), británicos (Herbert G. Wells), chilenos (Alejandro Jodorowsky), colombianos (René Rebétez), mexicanos (Juan José Arreola), polacos (Stanislaw Lem), checoslovacos (Josef Nesvadra), soviéticos (A. Dneprov), y, por supuesto, cubanos (Rogelio Llopis, Arnaldo Correa y Ángel Arango).

Aunque si bien pueda parecer que la URSS impuso hasta en la cf su sovietismo, también cabe preguntarse si fue más bien una inercia lógica y consecuente de la emulación de la URSS, de la importación de un modelo que las autoridades tropicales vieron como conveniente y probadamente efectivo. De acuerdo con W. Raymond Duncan, el concepto de influencia es un concepto que hay que problematizar. En su libro de 1985 (aún pues existiendo la URSS) The Sóviet Union and Cuba. Interest

\footnotetext{
${ }^{5}$ Efectivamente, el listado es más extenso. No conozco ningún estudio que recuente el número preciso de obras, pero los setenta vio una impresionante publicación de obras del mundo socialista, incluyendo cf de Polonia, Checoslovaquia, la RDA o incluso Vietnam.
} 
and Influence dice que "(...) influence happens less frequently than imagine, and what passes as influence is often a case of two countries simply pursuing compatible objectives” (Duncan, 1985: xiii). Y añade que en el caso concreto de la relación entre Cuba y la URSS esta influencia ha sido vista a partir de los setenta por algunos teóricos como “(...) Cuba as an autonomous actor where Castro used the Sóviets in quest of his own independent foreign policy goals” (Duncan, 1985: 2).

Sea uno u otro el caso, los autores de cf cubana no se quedaron al margen de esta situación, y la influencia de la cf de la esfera comunista hizo a la mayoría tomar partido. Algunos prefirieron aceptar las nuevas normas (creyeran o no en los principios que defendían) y otros buscaron subterfugios para publicar y decir cosas que no eran las estrictamente permitidas.

Desde el punto de vista de la publicación, la cf de los ochenta retomó las pautas de los sesenta e incluso las mejoró rápidamente. Esto fue posible, principalmente gracias a la implantación del premio nacional David de cf para jóvenes noveles en 1979 y que duró una década y dio gran visibilidad al género. Alrededor de este premio aparecen casi todos los autores relevantes de los ochenta y noventa que podemos nombrar en ambos grupos citados antes. Algunos de los premios nacionales de cf adjudicados tienen claros tintes del realismo socialista; pero en algunos casos la lectura ha de hacerse con cautela, ya que lo socialista sólo aparece aquí y allá, casi fuera de tono, casi incluso de forma ridícula, y cabe preguntarnos si apareció allí porque tenía que aparecer y no como parte integral del texto y de la ideología del autor. El caso, de todas formas, es que estos, si quieren, guiños a las autoridades editoriales están allí, impresas para siempre y nos permiten observar cómo y en qué medida se produjo la aparición de la ideología del estado en la cf cubana. Destacan algunas novelas que están plenamente inscritas en el realismo socialista y otras que tan sólo le hacen guiños al estado. De las segundas podríamos por ejemplo hablar de la colección de cuentos Los mundos que amo de Chaviano, sobre todo su versión en fotonovela, de Beatrice de Félix Lizárraga, y de Amor más acá de las estrellas de Enrique Morente, todas ellas premios David, y en las que aparecen menciones y alusiones a los logros del socialismo en el mundo. Como ejemplo, en el caso de Chaviano, se puede señalar que su cuento largo que da nombre a la colección permitió una interpretación prosoviética, con foto incluida del Kremlin, en la versión en fotonovela--repito--de 1982 (cuyo guión se anuncia como de Chaviano misma) (Chaviano, 1982: 33-34). Esto es especialmente curioso, si se tiene en cuenta que Chaviano es una de los máximos exponentes del grupo de autores que no se plegó a lo que el régimen prescribía y que veremos más adelante.

Sin embargo, otras obras premiadas con el David están claramente insertadas en la idea del realismo socialista cubano. Cabe destacar La nevada de Gabriel Céspedes y Eilder de L. A. Soto 
Portuondo. Ambas novelas reflejan los ideales de un realismo socialista cubano que mezcla el eterno optimismo del que nos hablaba Arango con el concepto de héroe socialista, amante de lo colectivo.

Aunque he dedicado bastante más espacio al análisis de este fenómeno en el artículo “El cyberpunk cubano: del realismo socialista al anarquismo capitalista" 6 , me parece necesario que el lector que no puede tener acceso a estas obras pueda ver un ejemplo de a qué me refiero. En Eilder, la novela de Soto Portuondo premiada con el David en 1983, el personaje doctor Cárdenas le explica a Eilder, el extraterrestre protagonista defendido por los humanos, cómo lo que hace a los cubanos un pueblo tan fuerte es su colectivismo:

Con todo el poder de esa fuerza ni tú, ni yo, ni él, nadie podrá hacer mucho actuando en forma particular. La verdadera potencia, la fuerza realmente incalculable se halla en el colectivo, en la acción común encaminada a fines justos, con propósitos de redención humana firmes y siempre válidos. (Soto, 1987: 147)

Pero sin lugar a dudas, los dos autores que con mejor éxito han integrado el realismo socialista en sus obras han sido Ángel Arango (de quien ya hablamos anteriormente) y Agustín de Rojas Anido, cuyo nombre como escritor fue Agustín de Rojas, y que sigue siendo reconocido entre sus fieles como el mejor escritor de cf cubana. Tal es su reconocimiento que aunque dejó de escribir cf en 1990, desengañado con la realidad expuesta por la caída del mundo socialista, unos de los pocos talleres de literatura de cf que existía en La Habana a comienzos del siglo XXI, se llamaba Espiral como la primera novela de Rojas ganadora del David de 1982, y cuya reedición se acaba de lanzar en el 2015 en Cuba ${ }^{7}$. Rojas escribió tres novelas de cf, Espiral, Una leyenda del futuro y El año 200, siendo esta última la más conseguida de las tres. En las tres novelas Rojas nos habla de un mundo que ha abrazo el socialismo como la única respuesta para la felicidad y la justicia humana. En Espiral una de las protagonistas, Noreen, afirma que, ante el peligro del enemigo imperialista "Nuestro puesto está aquí, en la primera fila" (Espiral, 1982: 405). Es una mujer de vanguardia. Y estos hombres y mujeres vanguardistas recuerdan a sus antepasados comunistas como los justicieros que ejemplificaron la posibilidad de una Tierra mejor para todos: "Más vale pensar que el Imperio ha existido siempre dominando toda la Tierra, que nunca existieron hombres que sacrificaron sus vidas por el comunismo, que lograron construir una sociedad justa sobre cuatro quintas partes del mundo" (Espiral, 1982: 404). Rojas inserta sus novelas en

\footnotetext{
6 Originalmente publicado en inglés como "From Socialist Realism to Anarchist-Capitalism: Cuban Cyberpunk" Science Fiction Studies 32-3 (2005): 442-466.

7 La recientemente creada editorial Ediciones Obrador (Montreal, Canadá), ha lanzado la colección de cf “Agustín”, nombrada así en honor a Rojas. Lo ha hecho con la novela de Yoss Angélica.
} 
Juan Carlos Toledano Redondo. Sputniks cubanos...

la tradición cubana socialista, así comienza Espiral con una cita del Che, e incluye en la novela la canción de Silvio Rodríguez "Al final de este viaje"8.

Volviendo a las ideas de Duncan sobre la influencia de la URSS en Cuba, no podemos concluir si esta influencia es activa o pasiva, si es sólo una herramienta del imperio soviético o una herramienta de control y reeducación de un sector de los lectores jóvenes en Cuba dirigida por las autoridades cubanas. Parece evidente, que ambas partes estaban preocupadas por objetivos similares y que la cf, las artes en general, eran un medio útil de lograr este objetivo. La influencia es pues más bien un proyecto común de ambas autoridades literarias. Si la URSS pone a disposición de Cuba a las editoriales Mir, Ráduga y Progreso, Cuba abre el mercado editorial soviético permitiendo que sólo sean sus obras de cf las que se publiquen en la isla en los setenta. Pero no podemos culpar a la URSS de abrir el premio David a la cf, o de apoyar la publicación de obras cubanas de ef en las editoriales más importantes del país como la UNEAC, Letras Cubanas, Unión y Dragón. Es posible afirmar, a la luz de lo expuesto, que la expansión de cierto tipo de cf cubana no es un caso de influencia soviética sino de estrategia de estado en Cuba, aunque los modelos usados sean externos y los resultados no tan pulidos como las autoridades deseaban. También hay que recordar que la "normalizalización" cultural de todo régimen que se mantiene en el tiempo, viene acompañada de la "normalización" de su producción artística local, cuya disyuntiva es adaptarse o morir (o exiliarse).

Sin embargo, y como indiqué más arriba, también apareció una cf de contradiscurso. Esta se podría dividir en dos, una que acompaña el resurgimiento de la ef en los ochenta, y otra que viene después, con el eufemísticamente llamado Periodo Especial tras la caída de la URSS. Hablaré brevemente de ambas, más brevemente incluso de las segunda de ellas.

La cf que apareció en los ochenta, se encontraba totalmente inmersa en la represión ideológica que existía en Cuba. Entre los muchos autores del momento, destaca un grupo de jóvenes que publica una of que se apega más a las doctrinas literarias de lo que se ha venido a llamar la Nueva Ola en la producción en inglés, sobre todo en Gran Bretaña y los EE.UU. En este grupo destacan Daína Chaviano, Cheli Lima y su marido Alberto Serret, y Antonio Orlando Rodríquez. Por otra parte, también me gustaría dedicar unas líneas al autor de cf humorística F. Mond, seudónimo de Féliz Mondéjar. De estos autores, sólo el último sigue viviendo en la isla. Orlando, Chaviano, Lima y Serret, la abandonaron en diferentes momentos antes de los noventa. Si bien Orlando escribió obras como la fantasía vampírica para niños Querido Drácula, Lima y Serret publicaron cf tanto por separado como en colaboración, siendo su

\footnotetext{
${ }^{8}$ En su última obra de cf, El año 200, de 1990, Rojas nos transporta a una sociedad poscomunista y eutópica y viaja a un mundo más allá del comunismo, donde se llegan a ver algunas grietas del sistema, si se hace una lectura muy cuidadosa del texto.
} 
colección de cuentos de 1983 Espacio abierto su publicación más significativa ${ }^{9}$. Por su parte, Chaviano es la más prolífica y afamada de todos, habiendo tenido un gran éxito mediático dentro de la isla, y más tarde, fuera de ella, una vez afincada en Miami y produciendo obras de estilo más realista. La literatura de este grupo de autores no era subversiva per se, ni fue nunca tildada de contrarrevolucionaria. Su contradiscurso se basaba en un claro anti-sovietismo, podríamos decir, basado en las formas más poéticas de su lenguaje, su uso de una dudosa ciencia que a ratos podía confundirse con magia, mitología e incluso directamente fantasía; lo cual se oponía de una forma más sutil pero clara, a las formas de la cf del campo socialista que había llegado en los setenta y ochenta. No era sólo que sus formas iban contra el estilo oficialista de la cf a la soviética, sino que además esas formas, esas discontinuidades genéricas, ponían en cuestión también las ideas uniformes que sobre la ciencia y los géneros literarios se trataban de defender desde el sovietismo cubano a partir del citado congreso de 1971.

Por su parte, F. Mond ${ }^{10}$ mantenía su particular lucha desde una perspectiva diferente. Haciéndose eco del famoso y admirado pionero poema de cf de Oscar Hurtado La ciudad muerta de Korad, creó novelas basadas en un universo donde los alienígenas eran koradianos y donde las historias eran paródicas y sarcásticas. Sobre todo la novela Krónicas koradianas, ya de 1988, es una clara alegoría de, entre otras cosas, el sistema comunista imperante en la isla. En específico el capítulo titulado "Nel mezzo del cammin di nostra vita..." dónde se parodia a La divina comedia, y en donde Virgilio, guía turístico del Cielo, explica cómo el propio Dios favorece el comunismo:

[Virgilio] - (...) Piense que aquí van a seguir llegando almas eternamente y hay que satisfacer sus necesidades materiales y espirituales. ¿De dónde sale todo eso, de la nada? ¡Pues no! La riqueza material y espiritual que usted ve en cada rostro de los que aquí habitan, es producto del trabajo personal: cada alma aporta según su capacidad y recibe de acuerdo a su necesidad.

[Green] - Pero...¡issa es la fórmula del comunismo!

[Virgilio] - Acaba usted de caerse de la mata. (Mond, 1988: 240)

F. Mond, empleado de la editorial Letras Cubanas, que nunca favoreció al sistema, utilizó la parodia como sistema de resistencia, y ha logrado con bastante facilidad evitar la censura de sus obras.

Finalmente, y ya escapando de la onda expansiva de los setenta y comienzos de los ochenta, no quiero dejar de citar --pero sólo eso, citar--a otro grupo más joven de autores que emergió y utilizó el

\footnotetext{
${ }^{9}$ Tal fue el éxito de esta obra de apenas noventa y dos páginas, que el taller y coloquio más importante de Cuba hoy se llama en honor de ambos autores Espacio abierto.

${ }^{10}$ Mención en el apartado de cf humorística en el David de 1982 con la novela Con perdón de los terrícolas.
} 
estilo ciberpunk venido de los EE.UU. (un poco tardíamente) como contradiscurso oficial. A la cabeza de este grupo está Yoss, ganador del David de 1988 con la colección Timshel, y con él aparecen nombres como Michel Encinosa y Vladimir Fernández, entre otros. Yoss y Encinosa han seguido publicando en la isla hasta la fecha, y a pesar de su discurso duro y subversivo, no han tenido problemas con las autoridades. Cierto es que la obra de Yoss Se alquila un planeta, con diferencia la más crítica sobre el Periodo Especial, tuvo que publicarse primero en España, y luego ha salido en francés e inglés, pero no se ha editado ninguna versión cubana hasta la fecha. Yoss es el autor más prolífico y afamado de la cf cubana actual, y hay bastantes estudios sobre su obra ${ }^{11}$.

Por su parte, Encinosa, con al menos diez colecciones de cuentos y novelas, es bastante conocido en Cuba, pero no ha tenido igual proyección internacional. No obstante, su historia "Un puñado de lluvia" de la colección Niños de neón, captura perfectamente el uso local del estilo cyberpunk para criticar al sistema totalitario cubano.

Pero como anuncié, no quiero entrar en esta parte de la historia de la cf y de Cuba. Ya otros lo hacen mejor que yo. La intención de estas páginas era exponer cómo una coyuntura concreta de la literatura de cf cubana fue marcada por la estrecha relación entre el mundo editorial de la URSS y su entorno, y la Cuba castrista de los setenta y ochenta. Espero haberlo conseguido.

${ }^{11}$ Véanse los artículos de Juan C. Toledano Redondo y de Emily A Maguire en bibliografía. 
Juan Carlos Toledano Redondo. Sputniks cubanos...

\section{Bibliografía citada}

Arango, Ángel. "La joven ciencia-ficción cubana. (Un lustro dentro del concurso David)." Unión 23-41 (1984): 128-138.

Céspedes, Gabriel. (1985) La nevada. La Habana: Ediciones Unión.

Chaviano, Daína (1980). Los mundos que amo. La Habana: Ediciones Unión.

Chaviano, Daína (1982). Los mundos que amo. La Habana: Editorial Gente Nueva.

Chaviano, Daína. "Para una bibliografía de la ciencia-ficción cubana." Letras Cubanas (1988): 273-278.

Claeys, Gregory and Tower Sargent, Lyman (1999). The Utopia Reader. New York: New York U. P.

Duncan, W. Raymond (1985). The Sóviet Union and Cuba. Interest and Influence. New York: Praeger.

Encinosa Fu, Michel (2001). “Un puñado de lluvia”. Niños de neón. La Habana: Letras Cubanas: 7-25.

Ferreras, Juan I. (1972). La novela de ciencia-ficción. Madrid: Siglo XXI.

Guevara, Ernesto y Deutschmann, David (1997). Che Guevara Reader: Writings by Ernesto Che Guevara on Guerrilla Strategy, Politics \& Revolution. Melbourne: Ocean Press.

Henríquez, Bruno (ed.) (2009). El hombre que hizo el mar Báltico. Editorial Arte y Literatura: La Habana.

Hurtado, Oscar (ed.) (1969). Cuentos de ciencia ficción. La Habana: Biblioteca del Pueblo.

Hurtado, Oscar (1964). La ciudad muerta de Korad. La Habana: Ediciones Revolución.

Lima, Chely y Serret, Alberto (1983). Espacio abierto. La Habana: Letras Cubanas.

Maguire, Emily A. "El hombre lobo en el espacio: el hacker como monstruo en el cyberpunk cubano". Revista iberoamericana 75, n. $^{\circ} 227$ (2009): 505-521.

March, Roselind J. (1986). Sóviet Fiction Since Stalin: Science, Politics and Literature. Totowa, N.J.: Barnes \& Noble.

Mond, F. (1988). Krónicas Koradianas. La Habana: Editorial Letras Cubanas. 
Orlando Rodríguez, Antonio. “¿Milicianos versus extraterrestres? Apuntes sobre la ciencia-ficción en Cuba." Conference on Cuban and Cuban-American Studies (8-20 Marzo, 1999). Florida International University, Miami.

Rojas Anido, Agustín (1982). Espiral. Ciudad de la Habana: Unión de Escritores y Artistas de Cuba.

Soto Portuondo, L. A. (1987). Eilder. La Habana: Ediciones Unión.

Tertz, Abram (1960). On Socialist Realism. New York: Pantheon Books.

Toledano Redondo, Juan Carlos. “Ángel Arango’s Cuban Trilogy: Rationalism, Revolution and Evolution”. Extrapolation (2002): 420-438.

Toledano Redondo, Juan Carlos. "El cyberpunk cubano: del realismo socialista al anarquismo capitalista” (traducción). Qubit. Boletín digital de literatura y pensamiento cyberpunk (2008): 3-19.

Toledano Redondo, Juan Carlos. "From Socialist Realism to Anarchist-Capitalism: Cuban Cyberpunk". Science Fiction Studies 32-33 (2005): 442-466.

Yoss (2012). "Marcianos en el platanal de Bartolo: un análisis de la historia y perspectivas de la ciencia ficción en Cuba al final del segundo milenio." La quinta dimensión de la literatura. Reflexiones sobre la ciencia ficción en Cuba y el mundo. La Habana: Editorial Letras Cubanas: 61-80. 